\title{
An Automatic Reaction Control Chemical Ionization Technique in Ion Trap Detector for Quantitative Plasma Profiling of Arecoline in Treated Alzheimer Patients
}

\author{
H. Umesha Shetty,* Eileen M. Daly, Nigel H. Greig,* Stanley I. \\ Rapoport, and Timothy T. Soncrant \\ Laboratory of Neurosciences, National Institute on Aging, National Institutes of Health, Bethesda, Maryland, \\ USA
}

\begin{abstract}
An automatic reaction control chemical ionization technique in an ion trap detector (ITD) was used to quantitate the levels of the cholinergic drug, arecoline, in plasma of treated patients with Alzheimer's disease. The chemical ionization reaction was carried out with acetonitrile. The protonated molecules of arecoline $(\mathrm{m} / \mathrm{z} 156)$ and the internal standard, homoarecoline $(m / z 170)$, were monitored. Human plasma samples were extracted with a readily evaporable solvent mixture, the residues reconstituted and injected along with a tertiary amine-carrier into a capillary gas chromatograph interfaced with the ITD. Standard curves for plasma-extracted arecoline between $20-\mathrm{ng} / \mathrm{mL}$ and $156-\mathrm{pg} / \mathrm{mL}$ levels were linear $(r>0.9980)$. Satisfactory precision (relative standard deviation $<20 \%)$ and accuracy (relative error $<15 \%$ ) at the limit of quantitation, $156 \mathrm{pg} / \mathrm{mL}$ arecoline, were achieved. Optimal conditions for handling of blood samples obtained by venipuncture were determined. The assay was successfully applied for the therapeutic monitoring of Alzheimer patients treated intravenously with arecoline. (I Am Soc Mass Spectrom 1991, 2, 168-173)
\end{abstract}

$\mathrm{N}$ europathological studies of Alzheimer's disease (AD) brains indicate a profound degeneration of cholinergic neurons in the basal forebrain $[1,2]$ and ventral striatum [3]. The activity of the acetylcholine synthesizing enzyme, choline acetyltransferase, is greatly diminished in the diseased brain, and the reduction is correlated with severity of dementia $[4,5]$ and the number of senile plaques [6]. However, the postsynaptic elements of the cholinergic synapses remain functionally intact; loss of cholinergic receptors in $\mathrm{AD}$ is similar to that of age-matched controls [7].

The preservation of central cholinergic receptors in $\mathrm{AD}$, together with the discovery of a link between the cholinergic system and memory function [8], has led to therapeutic trials of cholinergic agonists to improve the cognitive function of AD patients., Arecoline (1), the principal alkaloid of Areca catechu, is a muscarinic cholinergic agonist that readily crosses the blood-brain barrier. Although the alkaloid has been reported to enhance memory in normal healthy subjects [9], its therapeutic value in $\mathrm{AD}$ remains uncertain [10] due potentially to a failure in previous studies to achieve and maintain a pharmacologically adequate brain concentration.

Comprehensive evaluation in our laboratory of

*Present address Athena Neurosciences Inc., South San Francisco, California.

Address reprint requests to $H$. Umesha Shetty, Athena Neuro sciences Inc., 800 F, Gateway Boulevard, South San Francisco, CA 94080 . cholinergic supplementation therapy in $A D$ required pharmacokinetic analyses of arecoline in human plasma and cerebrospinal fluid. Hence, a highly sensitive and reliable assay procedure was necessary to monitor low- and variable-dose regimens of this cholinergic drug. The only reported procedure for plasma quantitation of arecoline is a combined capillary gas chromatography (GC) and ammonia chemical ionization (CI) mass spectrometry with a detection limit from plasma of $1 \mathrm{ng} / \mathrm{mL}$ [11]. The present assay utilizes a CI technique in an ion trap detector (ITD) and homoarecoline (2) [12] as an internal standard. While offering a significantly improved sensitivity, the technique described here is devoid of chromatography problems of the reported procedure. Also, this ion trap methodology could readily be transformed to a high-throughput assay suitable for routine monitoring.

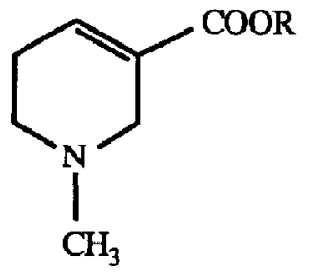

$$
\begin{array}{ll}
1 & \mathrm{R}=\mathrm{CH}_{3} \\
2 & \mathrm{R}=\mathrm{CH}_{2} \mathrm{CH}_{3}
\end{array}
$$




\section{Experimental}

Materials. High-performance liquid chromatographic (HPLC)-grade solvents were used: diethyl ether, nhexane, and ethyl acetate were obtained from Fluka Chemical Corporation (Ronkonkoma, NY), and npentane and acetonitrile from Burdick \& Jackson (Muskegon, MI). Reagents, $N$-ethyldiisopropylamine and 1,3-diphenyl-1,1,3,3-tetramethyldisilazane, were purchased from Fluka Chemical Corporation. Arecoline. $\mathrm{HBr}$ was purchased from Sigma Chemical Company (St. Louis, MO). The free base was obtained by basifying with $\mathrm{Na}_{2} \mathrm{CO}_{3}$, extracting with diethyl ether, and then distilling in vacuo. Homoarecoline was prepared in our laboratory by esterifying arecaidine. $\mathrm{HCl}$ (Sigma) with ethanol. The free base was isolated, purified by microdistillation, and treated with $\mathrm{HBr}$ to yield homoarecoline. $\mathrm{HBr}$. This salt was recrystallized from $n$-propanol, mp $125-127^{\circ} \mathrm{C}$ (ref $12,105^{\circ} \mathrm{C}$ ). The structure and purity $(>99 \%)$ of homoarecoline were ascertained by ${ }^{1} \mathrm{H}$ nuclear magnetic resonance and GC/MS analyses.

Buffer solution, $\mathrm{pH}$ 9, was prepared by adding ammonium hydroxide to $2 \mathrm{M}$ ammonium chloride, and was stored at $4^{\circ} \mathrm{C}$. Pyrex disposable culture tubes (10 mL; PGC Scientifics, Gaithersburg, MD) with Teflon-lined caps (PGC Scientifics) were used for plasma extractions. Disposable tapered centrifuge tubes (5 mL; PGC Scientifics) were used to collect and evaporate the organic extracts. The sample handling tubes were silanized with dimethyldichlorosilane in $n$-hexane, rinsed with methanol, acetonitrile, and air dried. Multitube vortexing was carried out in a Tekmar (Cincinnati, OH) Vibrax VXR2 shaker. A Sorvall RT 6000B Refrigerated Centrifuge (Du Pont, Wilming. ton, DE) was used for separation of the layers after plasma extraction. Evaporation was carried out in a Pierce (Rockford, IL) Reacti-Therm ${ }^{\mathrm{TM}}$ III evaporator. The delivery needles of the evaporator were soaked in $5 \%$ acetic acid, washed, and dried after each usage. Nitrogen gas was used for evaporation and was purified by an In-Line Gas Purifier (Alltech Associates, Inc., Deerfield, IL). Blank human plasma samples were obtained from the blood bank at the National Institutes of Health (Bethesda, MD).

Gas chromatograph / mass spectrometer (GC/MS) system. A Finnigan (San Jose, CA) Mat 700 Ion Trap Detector (ITD ${ }^{\mathrm{M}}$ ), equipped with Revision 4.0 Automatic Reaction Control Chemical Ionization (ARC-CI) software, was coupled to a Perkin-Elmer (Norwalk, CT) Sigma 2000 gas chromatograph through a capillary column, without a flow restrictor. The GC setup featured a split/splitless inlet system with a narrow-bore glass insert, a septum needle guide, teflon-lined septum (Alttech), and a J\& W (Bodman Chemicals, Aston, PA) DB-5 fused-silica capillary column of 30-m $\times 0.25$ $\mathrm{mm}$ dimensions and $0.2-\mu \mathrm{m}$ film thickness. Helium was used as a carrier gas. It was purified by passing through gas purifiers and oxy-traps (Alltech). A linear velocity of $30 \mathrm{~cm} / \mathrm{s}$ at $150^{\circ} \mathrm{C}$ for helium was maintained through the capillary column. A split vent flow of $44 \mathrm{~mL} / \mathrm{min}$ and septum purge flow of $4 \mathrm{~mL} / \mathrm{min}$ were allowed at the inlet system. The transfer line and manifold temperatures of the ITD were maintained at 200 and $220^{\circ} \mathrm{C}$, respectively. The injector temperature of the $\mathrm{GC}$ was held at $170^{\circ} \mathrm{C}$. Samples were injected at an oven temperature of $50^{\circ} \mathrm{C}$, and after a 30-s delay, the temperature was ramped to $150^{\circ} \mathrm{C}$ at $20^{\circ} \mathrm{C} / \mathrm{min}$ and thereafter at $4^{\circ} \mathrm{C} / \mathrm{min}$ to $160^{\circ} \mathrm{C}$ and maintained temperature for $1 \mathrm{~min}$. The temperature program was terminated after heating the column at $180^{\circ} \mathrm{C}$ for $0.5 \mathrm{~min}$. Samples were injected into the GC in the splitless mode for $45 \mathrm{~s}$. Prior to analysis of samples, 1,3-diphenyl-1,1,3,3-tetramethyldisilazane $(0.5 \mu \mathrm{L})$ was injected into the $\mathrm{GC}$ at $200^{\circ} \mathrm{C}$ in the split mode of operation. After one hour at this temperature, the GC was conditioned at $100^{\circ} \mathrm{C}$ overnight. The septum and glass liner were replaced after approximately 50 injections. The liners were reused after cleaning with methanol and $30 \%$ boiling $\mathrm{HNO}_{3}$, rinsing with distilled water, and drying.

Chemical ionization was carried out with acetonitrile reagent gas. For this, HPLC-grade acetonitrile (Burdick \& Jackson) was placed in a vial and its vapor was introduced into the ITD source via a metering valve at ambient temperature. Since the partial pressure of the reagent gas could not be monitored on the ITD, the metering valve was adjusted to give $3000-4000$ counts for the protonated acetonitrile, $\mathrm{m} / z$ 42. This was done in the instrumental setup mode of the software at $200 \mathrm{~V}$ below a $10^{5}$-gain voltage setup of the electron multiplier. Parameters for the reaction were optimized as follows: peak height of the reagent ion was plotted against a range of ionization radio frequency (rf) levels to determine an optimum value (135.5 mV, $8.6 \mathrm{u}$ in the software) for its efficient trapping, and, analogously, the reaction if level (283.5 $\mathrm{mV}, 18 \mathrm{u}$ in the software) for trapping of the product ion was chosen by measuring the ion current for the protonated arecoline (on-column $1.5 \mathrm{ng}$, triplicate) at different rf levels. Maximum ionization time and reaction time used were $700 \mu \mathrm{s}$ and $40 \mathrm{~ms}$, respectively. Both background mass and low scan limit were set at $120 \mathrm{u}$. A filament current of $60 \mu \mathrm{A}$ and an electron multiplier voltage of $50-100 \mathrm{~V}$ above the $10^{5}$-gain voltage were utilized for detection. Data were acquired only over the mass range $155-171 \mathrm{u}$ in the normal ITD scan acquisition mode. This allowed the averaging of 16 scans every half-second by the data system for final output. Reconstructed ion chromatograms were created postrun $(\mathrm{m} / \mathrm{z} 156$ and 170 for arecoline and homoarecoline, respectively). The operating sensitivity (parameter " $B$ " of the software) of the mass spectrometer was 2700 units.

Preparation of stock solutions and plasma standards. Equivalent amounts of arecoline. $\mathrm{HBr}$ or homoarecol- 
ine. $\mathrm{HBr}$ were dissolved in a mixture of acetonitrile and ethyl acetate $(95: 5, \mathrm{v} / \mathrm{v})$ to provide stock solutions containing $1 \mathrm{mg} / \mathrm{mL}$ of free base. Stock solutions were stored at $4^{\circ} \mathrm{C}$ and changed monthly. A working standard solution of arecoline $(20 \mathrm{ng} / \mathrm{mL})$ was prepared daily. An aliquot of this solution was serially diluted to obtain $10 \mathrm{ng}, 5 \mathrm{ng}, 2.5 \mathrm{ng}, 1.25 \mathrm{ng}$, $625 \mathrm{pg}, 312.5 \mathrm{pg}$, and $156 \mathrm{pg}$ of atecoline, each in 100 $\mu \mathrm{L}$. The stock solution of homoarecoline was diluted to provide a concentration of $25 \mathrm{ng}$ in $100 \mu \mathrm{L}$. These dilutions were carried out in silanized tubes with the same solvent mixture used for preparing the stock solutions. Blank human plasma samples $(1 \mathrm{~mL})$ were cooled to $4^{\circ} \mathrm{C}$, spiked with $100 \mu \mathrm{L}$ of each of the working standard solutions ( $20 \mathrm{ng}$ to $156 \mathrm{pg}$ ) of arecoline, and mixed. The resulting standard plasma samples used for the generation of the standard curve were prepared on each day of analysis.

Extraction procedure. Standard plasma samples or plasma (1 $\mathrm{mL}$ each) obtained from patients receiving arecoline were spiked with $100-\mu \mathrm{L}$ aliquots $(25 \mathrm{ng}$ ) of the internal standard, homoarecoline, solution. The contents of the tubes were mixed and basified by the addition of $100 \mu \mathrm{L}$ of ammonia buffer ( $2 \mathrm{M} ; \mathrm{pH} 9)$. A mixture of pentane and diethyl ether $(80: 20, \mathrm{v} / \mathrm{v})$ was cooled to $4^{\circ} \mathrm{C}$ in a dispenser, and $5 \mathrm{~mL}$ delivered to each tube. These were vortexed for $5 \mathrm{~min}$ and then centrifuged at $1000 \mathrm{~g}$ for $5 \mathrm{~min}$ at $4^{\circ} \mathrm{C}$. The tubes were immersed in dry ice until the aqueous layers froze, and the top organic layers were poured into tapered centrifuge tubes. The organic extracts were concentrated by evaporating the solvents under a stream of $\mathrm{N}_{2}$ gas at $80-\mathrm{mL} / \mathrm{min}$ flow. The heating blocks of the evaporator were at ambient temperature. The residues were reconstituted in $25 \mu \mathrm{L}$ of $n$-hexane containing $1 \%$ N-ethyldiisopropylamine, and $1.5-\mu \mathrm{L}$ aliquots were injected into the GC/MS.

Recovery study. Plasma recovery of arecoline at a concentration of $10 \mathrm{ng} / \mathrm{mL}$ was determined by using homoarecoline (free base) as an external standard. Six replicate spiked plasma samples were extracted, 4-mL aliquots of the organic layers were removed, $25 \mathrm{ng}$ of homoarecoline was added to each, mixed, and solvent evaporated. The amount of arecoline partitioned into the organic phase was determined from the calibration curve generated by the use of homoarecoline (free base) as an internal standard. The absolute amount of arecoline recovered in $5 \mathrm{~mL}$ of the organic phase was calculated and expressed as a percentage of the added amount.

Stability study. Freshly drawn human whole blood, $10 \mathrm{~mL}$, was placed in heparinized tubes in a $37^{\circ} \mathrm{C}$ water bath. An aqueous solution of arecoline. $\mathrm{HBr}$ was added to each tube to a final concentration equivalent of $10 \mathrm{ng} / \mathrm{mL}$ free base. Immediately, duplicate samples were incubated at $37^{\circ} \mathrm{C}$, room temperature $\left(21^{\circ} \mathrm{C}\right.$ ), and $4^{\circ} \mathrm{C}$. Samples of blood, $2 \mathrm{~mL}$, were removed from each tube at $0-, 10-, 30-$, and 60-min intervals, the plasma separated and frozen to $-80^{\circ} \mathrm{C}$. Arecoline levels in these samples were quantitated after the addition of the internal standard. In a separate study, human plasma spiked with arecoline, 1.25 $\mathrm{ng} / \mathrm{mL}$, was stored at $-80^{\circ} \mathrm{C}$ for four months and then quantitated.

Precision and accuracy. Within-day assay precision was determined by spiking six replicate plasma samples with arecoline at concentrations of $10 \mathrm{ng} / \mathrm{mL}$, $1.25 \mathrm{ng} / \mathrm{mL}$, and $156 \mathrm{pg} / \mathrm{mL}$. Amounts were quantitated on the same day with a standard curve. Between-day variation was determined at a concentration of $1.25 \mathrm{ng} / \mathrm{mL}$. This amount of arecoline contained in a pooled blank plasma $(10 \mathrm{~mL})$, was divided into $1-\mathrm{mL}$ portions and stored at $-80^{\circ} \mathrm{C}$. The frozen samples were analyzed for arecoline content on separate days from different calibration curves generated over a period of four months.

\section{Results and Discussion}

Critical to the development of a sensitive and reproducible assay for arecoline is a judicious choice of the sample preparation procedure and instrumentation setup, compatible with the sensitive physicochemical properties of the molecule. The volatility, hydrolytic breakdown, and adsorptive nature of arecoline were considered in all stages of the assay.

Ion trap detection. Ion traps have gained popularity as sensitive and reliable mass spectrometers in recent years. As they are trapping devices and capable of producing a large population of reagent ions at a lower reagent gas pressure compared to conventional mass spectrometers, ion traps are readily adaptable to perform CI reactions. In our work, the ITD was found to provide approximately 10 times more sensitivity in ARC-CI mode than in electron ionization [13], when other variables are constant. This is true irrespective of the nature of the analyte (standard or plasma-extracted sample).

Acetonitrile as reagent gas. The traditional reagent gas, methane, causes significant hydride abstraction of arecoline. This process is significantly less pronounced if CI reaction is carried out with acetonitrile. The usefulness of acetonitrile as a reagent gas for ITD was previously reported [14]. The ion-molecule reaction of acetonitrile in the ITD source yields approximately $90 \%$ of the protonated molecule, $m / z 42$, and $10 \%$ of an adduct ion, $m / z 54$. The latter ion may be due to isomeric $\left[\mathrm{C}_{3} \mathrm{H}_{4} \mathrm{~N}\right]^{+}$species $[15,16]$. When deuterated acetonitrile $\left(\mathrm{C}^{2} \mathrm{H}_{3} \mathrm{CN}\right)$, alone or mixed with equimolar protio analogue, was introduced into the source, expected deuterium mass shifts for these ionic species were observed. The coefficient of varia- 
tion for the reagent ion count was less than $4 \%$ when checked periodically over a period of eight hours. This indicates a constant flow of acetonitrile vapor into the ITD source, a desirable characteristic of a CI gas, particularly for use in quantitative studies. The ARC-CI parameters for this reagent gas also were optimized in its present quantitation usage.

Capillary GC. Standard or plasma-extracted arecoline samples were eluted off the capillary column as single sharp peaks with minimum interference from the matrix components. This required optimization of the temperature program as well as injector temperature. Also at the chosen temperature $\left(170^{\circ} \mathrm{C}\right)$ of the injector, most of the high-boiling components of the plasma extract were retained in the sleeve of the inlet, and as a result the life of the column was prolonged. After removal of an approximately $1-\mathrm{cm}$ piece, the capillary column was periodically rejuvenated by injecting a small amount of silylating agent, 1,3-diphenyl1,1,3,3-tetramethyldisilazane [17]. The column performance was found to remain unaffected even after analysis of 1000 samples.

Choice of intemal standard. The selection of internal standards (labeled or unlabeled) for ion traps in quantitations has been discussed in earlier works $[18,19]$. In these, the traps were operated in rf-only, $\mathrm{rf} / \mathrm{dc}$ or rf/dc tandem mass spectrometry modes under electron ionization. A homologue of arecoline, homoarecoline, rather than an isotopically labeled analogue was found suitable in the present ARC-CI setup of ITD. This program linearly adjusts both ionization time and reaction time, while detecting a wide range of concentrations of an analyte, to prevent spacecharge effects [20]. In such a setup, detection of a relatively high concentration of internal standard and low concentration of analyte in the same time domain, as in quantitation with a co-eluting isotopically labeled internal standard, may not be achievable. When $\left[{ }^{2} \mathrm{H}_{5}\right.$ larecoline [21] was used as an internal standard for plasma quantitation of arecoline, subnanogram level of quantitation was not attainable. Typically, below $1.25 \mathrm{ng} / \mathrm{mL}$ level of andyte detections, peaks were poorly defined and accompanied by loss of linear response. It appears that for arecoline and perhaps other analytes, chemical analogues are appropriate internal standards for sensitive quantitations using ITD in its current scan functions. Conversely, in narrow dynamic ranges ARC-CI detections with labeled internal standards may be achievable.

Extraction and reconstitution. A suitable solvent system and conditions for extraction were determined to optimize both quality and yield of the analyte, arecoline, from human plasma. The effect of $\mathrm{pH}$, ranging between 4 and 12, on the partitioning of arecoline between aqueous layer and organic phase was studied. Maximum arecoline was recovered at $\mathrm{pH}$ 9.0; a

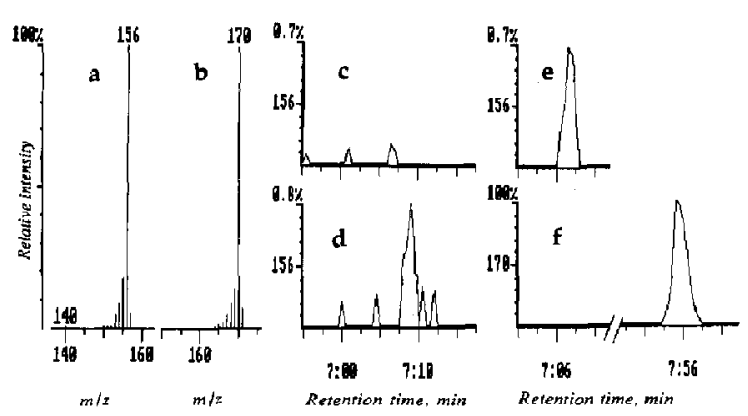

Figure 1. Acetonitrile CI spectra of (a) arecoline and (b) homoarecoline; and ion chromatograms for (c) control blank plasma, (d) plasma spiked with $156 \mathrm{pg} / \mathrm{mL}$ arecoline, (e) estimated $139 \mathrm{Pg} / \mathrm{mL}$ arecoline in the plasma of an Alzheimer patient 62 min after termination of continuous intravenous infusion of the drug, and (f) $25 \mathrm{ng} / \mathrm{mL}$ internal standard; $1 \mathrm{~mL}$. plasma was used in each case.

higher $\mathrm{pH}$ reduced recovery, probably as a consequence of hydrolysis. Therefore, plasma samples were extracted at $\mathrm{pH} 9.0$ to obtain optimal recovery of the analyte. The use of a relatively high-boiling-point solvent, such as ethyl acetate, proved unsuitable for extraction, as significant amount of arecoline is lost by evaporation (data not shown). A volatile solvent, such as diethyl ether, obviated this problem, but drying of the hydrated solvent posed another procedural difficulty. Subsequently, a mixture of n-pentane and diethyl ether $(80: 20 \mathrm{v} / \mathrm{v})$ was found to provide a clean extraction of arecoline from the plasma. A fivefold excess of this solvent mixture was used for maximum recovery of the analyte in a single extraction. After solvent evaporation, the residue was reconstituted in $n$-hexane containing $1 \% N$-ethyldiisopropylamine. This nonnucleophilic amine, while maintaining a basic milieu in the inlet and column, served as a good carrier for both the amines, arecoline and homoarecoline (internal standard), which were injected in nanogram-to-picogram amounts. Co-injection of $N$-ethyldiisopropylamine greatly reduccd peak tailing and improved the linearity of detection.

Acquisition. The acetonitrile CI mass spectra of arecoline and homoarecoline are shown in Figure 1a and $b$, respectively. A segment of ions, inclusive of $\mathrm{m} / z 156$ and 170 for protonated arecoline and homoarecoline, respectively, was monitored in the plasma quantitations. Peaks for the individual ion current of arecoline and the internal standard were then constructed. Figure $1 \mathrm{c}$ and $\mathrm{d}$ show the ion chromatograms for control blank plasma and for plasma spiked with arecoline $(156 \mathrm{pg} / \mathrm{mL})$, respectively. An ion chromatogram for the internal standard $(25 \mathrm{ng} / \mathrm{mL})$ is shown in Figure 1f. Peaks for arecoline and homoarecoline appeared with retention times of $7 \mathrm{~min} 8 \mathrm{~s}$ and $7 \mathrm{~min} 56 \mathrm{~s}$, respectively. Occasionally, weak peaks, possibly of electron multiplier noise or of chromatographic background, occurred in the vicinity of the arecoline peak 


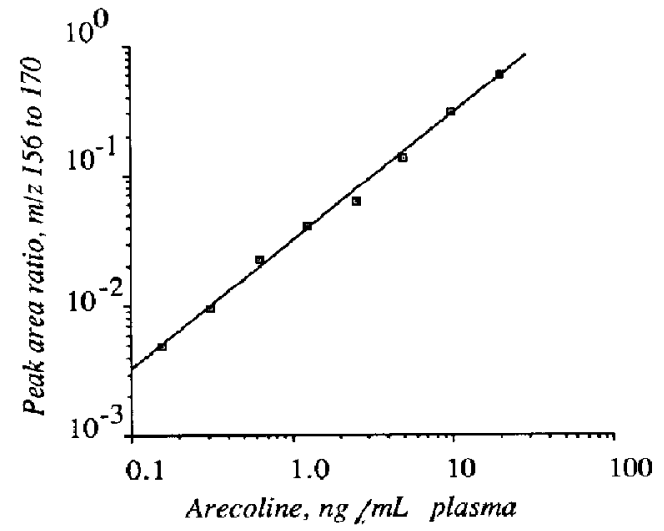

Figure 2. Representative standard curve generated by plotting logarithmic concentrations of arecoline ( $\mathrm{ng} / \mathrm{mL}$ plasma) versus logarithmic peak area ratios, arecoline to the internal standard; $y=0.0307 x^{8.9672}, r=0.9980$.

when quantitating low concentrations, $156 \mathrm{pg} / \mathrm{mL}$ (Figure 1d). However, these sporadic peaks made up less than $10 \%$ of the signal peak and their effect on the accuracy of the assay is insignificant.

Sensitivity and linearity. The lower limit of detection of a standard amount of arecoline by GC/MS was not determined, although for spiked plasma it was 78 $\mathrm{Pg} / \mathrm{mL}$, at a signal-to-noise ratio of 4 . The lower limit of quantitation was $156 \mathrm{pg} / \mathrm{mL}$. In all analyses only $6 \%$ of the final sample was injected to GC/MS, resulting in $9.4 \mathrm{pg}$ to $1.2 \mathrm{ng}$ of analyte on-column with 1.5 ng internal standard. Standard curves were constructed by plotting logarithmic ratios of the peak areas of arecoline $(m / z$ 156) to the internal standard $(m / z 170)$ against the logarithmic plasma concentrations of arecoline. Regression lines, generated by using logarithmic data, provided accurate estimates of unknown amounts of arecoline over a hundredfold concentration range. A typical standard curve illustrating the linearity $(r=0.9980)$ of detection for an arecoline concentration range between $20 \mathrm{ng} / \mathrm{mL}$ and $156 \mathrm{pg} / \mathrm{mL}$ is shown in Figure 2.

Recovery and reproducibility. Using homoarecoline free base as an external standard, quantitation of arecoline

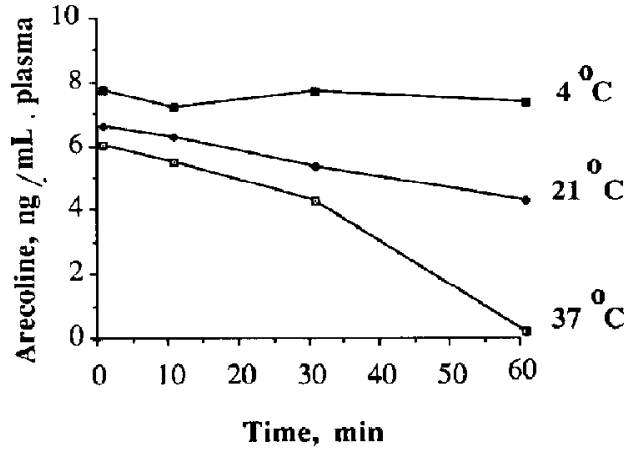

Figure 3. Effect of incubation temperature on the stability of arecoline $(10 \mathrm{ng} / \mathrm{mL})$ in human whole blood.

in the organic phase following extraction from plasma allowed the determination of percentage recovery. At a concentration of $10 \mathrm{ng} / \mathrm{mL}$, the recovery of arecoline was $89 \pm 6 \%$ (mean \pm s.d., $n=6$ ). Reproducibility of the assay was evaluated by replicate analyses of the spiked plasma samples at the limit of quantitation and also at higher concentrations along the standard curve. The precision (relative standard deviation of replicate analyses) and accuracy (relative error of the measurements) of the assay are summarized in Table 1 . These are satisfactory for both within-day and between-day variations, and therefore the assay procedure is applicable for routine therapeutic monitoring of arecoline.

Stability. During therapeutic monitoring, it is assumed that the drug remains undegraded between the time blood is withdrawn from treated subjects and the time plasma is separated and frozen for storage. Arecoline is rapidly hydrolyzed to its carboxylic acid, arecaidine, in liver homogenate preparations [22]. This labile ester probably is hydrolyzed in blood by acetylcholine esterase and nonspecific esterases. To minimize the loss of analyte during handling of blood and plasma prior to analysis, the effect of temperature on the stability of arecoline in the blood was studied. Arecoline was incubated in fresh human blood at $37^{\circ} \mathrm{C}, 21^{\circ} \mathrm{C}$ (room temperature), and $4^{\circ} \mathrm{C}$, and analyzed during $60 \mathrm{~min}$. Figure 3 shows that arecoline is minimally metabolized in blood up to $60 \mathrm{~min}$ if main-

Table 1. Precision and accuracy data

\begin{tabular}{lccccr}
\hline Precision type & Concentration added & $\begin{array}{c}\text { Concentration found } \\
\text { (mean } \pm \text { s.d.) }\end{array}$ & $\begin{array}{c}\text { Number of } \\
\text { replicates }\end{array}$ & $\begin{array}{c}\text { Relative standard } \\
\text { deviation }(\%)^{\mathrm{a}}\end{array}$ & $\begin{array}{c}\text { Relative } \\
\text { error }(\%)^{\mathrm{b}}\end{array}$ \\
\hline \hline Within-day & $10 \mathrm{ng} / \mathrm{mL}$ & $10.72 \pm 0.43 \mathrm{ng} / \mathrm{mL}$ & 6 & 4.0 & +7.2 \\
& $1.25 \mathrm{ng} / \mathrm{mL}$ & $1.22 \pm 0.13 \mathrm{ng} / \mathrm{mL}$ & 6 & 10.8 & -2.4 \\
& $156 \mathrm{pg} / \mathrm{mL}$ & $175 \pm 27 \mathrm{pg} / \mathrm{mL}$ & 6 & 15.5 & +12.2 \\
Between-day & $1.25 \mathrm{ng} / \mathrm{mL}$ & $1.36 \pm 0.07 \mathrm{ng} / \mathrm{mL}$ & 5 & 5.1 & +8.8 \\
\hline
\end{tabular}

(s.d. $/ \bar{X}$ ) 100

"[(Concentration found - concentration added]/concentration added] $\cdot 100$ 


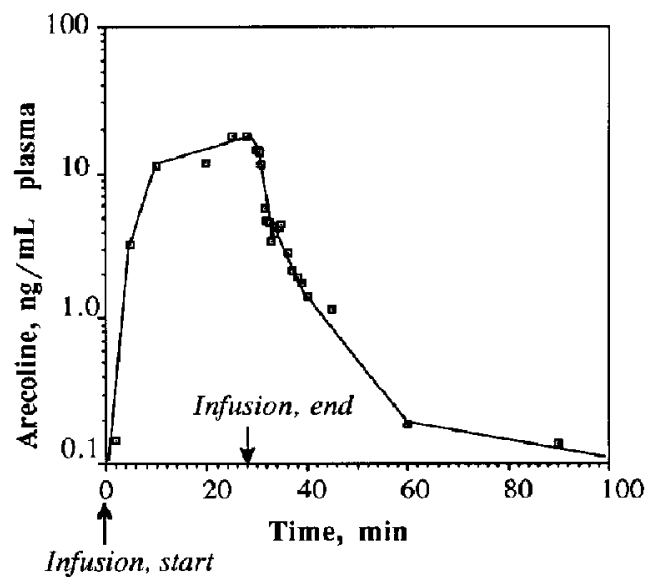

Figure 4. Plasma concentration time course of arecoline following a 28-min continuous intravenous infusion of arecoline, 5 $\mathrm{mg}$, to a patient with Alzheimer's disease.

tained at $4^{\circ} \mathrm{C}$. Therefore, blood samples from treated patients were collected in chilled tubes and immersed immediately in an ice bath. Plasma was immediately separated at $4^{\circ} \mathrm{C}$ and frozen. The stability of arecoline was checkęd in frozen plasma samples. No degradation of arecoline, $1.25 \mathrm{ng} / \mathrm{mL}$, occurred in plasma during four months of storage at $-80^{\circ} \mathrm{C}$.

Therapeutic monitoring. The applicability of this analytical technique was tested in human studies. In one clinical evaluation, AD patients received a 5-my dose of arecoline as a continuous intravenous infusion over a period of $28 \mathrm{~min}$. Blood samples were collected at timed intervals during infusion and up to $60 \mathrm{~min}$ postinfusion to determine the disposition characteristics of the drug. A time-dependent plasma concentration profile of arecoline in one subject is shown in Figure 4 . The assay procedure proved sufficiently sensitive and specific to precisely measure concentrations at the terminal portion of the curve without interference from metabolites or endogenous compounds. The ion chromatogram for the last estimated arecoline concentration, $139 \mathrm{pg} / \mathrm{mL}$, on the time-dependent concentration profile is shown in Figure 1e.

The pharmacokinetic analysis of arecoline in AD patients, including its efficacy in relation to plasma levels, will be reported elsewhere.

\section{Acknowledgments}

We wish to thank Dr. H. K. Lim, University of Utah, Salf Lake City, and Drs. M. Micklus and D. Purdon for their most valuable comments and advice during the preparation of this article.

\section{References}

1. Whitehouse, P. J.; Price, D. L.; Struble, R. G.; Clark, A. W.; Coyle, J. T.; DeLong, M. R. Science 1982, 215, 1237-1239.

2. Doucette, R.; Fisman, M.; Hachinski, V. C.; Merksy, H. Can. J. Neurol. Sci. 1986, 13, 435-440.

3. Lehericy, S.; Hirsch, E. C.; Cervera, P.; Hersh, L. B.; Hauw, J.-J.; Ruberg, M.; Agid, Y. Proc. Natl. Acad. Sci. USA 1989, 86, 8580-8584.

4. Bird, T. D.; Stranahan, S.; Sumi, S. M.; Raskind, M. Ann. Neurol. 1983, 14, 284-293.

5. Perry, E. K.; Tomlinson, B. E.; Blessed, G.; Bergman, K.; Gibson, P. H.; Perry, R. H. Br. Med. I. 1978, 2, 1457-1459.

6. Perry, R. H.; Perry, E. K. In Aging of the Brain and Dementia; Amaducci, L, Davison, A. N., and Antuno, P., Eds. Raven Press: New York, 1980; p. 167.

7. Quirion, R.; Martel, J. C.; Robitaille, Y.; Etienne, P.; Wood, P.; Nair, N. P. V.; Gauthier, S. Can. I. Neurol. Sci. 1986, 13, 503-510.

8. Bartus, R. T.; Dean, R. L.; Beer. B.; Lippa, A, S. Science 1982, 217, 408-417.

9. Sitaram, N.; Weingartner, H.; Gillin, J. C. Science 1978, 201, 274-276.

10. Christie, J. E.; Shering, A.; Ferguson, J.; Glen, A. L. M. Br. J. Psychiat. 1981, 138, 46-50.

11. Hayes, M. J.; Khemani, L.; Bax, M.; Alkalay, D. Biomed. Environ. Mass Spectrom. 1989, 18, $1005-1009$.

12. Dobrowsky, A. Monatsh. Chem. 1952, 83, 443-447.

13. Shetty, H. U.; Greig, N. H.; Soncrant, T. T.; Rapoport, S. I. Proceedings of the 37th ASMS Conference on Mass Spectrometry and Allied Topics, Miami Beach, FL, May 1989.

14. Lim, H. K.; Sakashita, C. O.; Foltz, R. L. Rapid Commun. Mass Spectrom. 1988, 2, 129-131.

15. Heerma, W.; Sarneel, M. M.; Dijkstra, G. Org. Mass Spectrom. 1986, 21, 681-687.

16. Wincel, H.; Wlodek, S.; Bohme, D. K. Int. I. Mass Spectrom. Ion Processes 1988, 84, 69-87.

17. Grob, K. J. High Resolut. Chromatogr. Chromatogr. Commun. 1980, 3, 493-496.

18. Strife, R. J.; Simms, J. R. Anal. Chem. 1989, 61, 2316-2319.

19. Strife, R. J.; Simms, J. R.; Lacey, M. P. J. Am. Soc. Mass Spectrom. 1990, 1, 265-271.

20. Weber, G. M.; Kelley, P. E.; Syka, J. E. P.; Bradshaw, S. C.; Brodbelt, J. S. Proceedings of the 35th ASMS Conference on Mass Spectrometry and Allied Topics, Denver, CO, May 1987.

21. Shetty, H. U.; Soncrant, T. T.; Greig, N. H.; Rapoport, S. I. J. Labelled Compd. Radiopharm., 1990, 28, 1025-1032.

22. Nieschulz, V. O.; Schmersahl, P. Arzneim.-Forsch. (Drug. Res.) 1968, 18, 222-225. 